\title{
Quantitative and Morphological Evaluationof Cancellous and Cortical Bone of the Mandible
}

\author{
Sudheendraswamy V.B. ${ }^{1}$, Rudresh S Halawar ${ }^{2}$ \\ ${ }^{1}$ Assistant Professor, ${ }^{2}$ Associate Professor, S. Nijalingappa Medical College, Bagalkot, Karnataka, India
}

Corresponding author: Dr. Rudresh S Halawar, Department of Radio-Diagnosis and Imaging, S. N. Medical College, Navanagar, Bagalkot, Karnataka. 587101, India

DOI: http://dx.doi.org/10.21276/ijcmsr.2019.4.4.34

How to cite this article: Sudheendraswamy V.B., Rudresh S Halawar. Quantitative and morphological evaluationof cancellous and cortical bone of the mandible. International Journal of Contemporary Medicine Surgery and Radiology. 2019;4(4):D146-D149.

\section{A B S T R A C T}

Introduction: To determine the quantity and morphology of bone, it is important for planning the implant placement in the mandible. In this study, the $\mathrm{CAB}$ and $\mathrm{COB}$ thickness in the mandible was precisely and accurately measured in five sections from $6 \mathrm{~mm}$ anteriorly to $18 \mathrm{~mm}$ posteriorly to the mental foramen.

Material and methods: This study included 90 patients out of which 50 were males and 40 were females, who had an age range of $20-80$ years, mean age of 50 years were selected in S.Nijalingappa Medical College Bagalkot. They underwent computed tomography between July 2017 to January 2019.

Results: 140 sides in total of mandibles, 688 heights, 2731 cancellous and 2731 cortical thicknesses were measured. In both genders, the $C A B$ thickness was the greatest in sections 2 and 5 and the COB thickness was greatest in sections 1 and 5 . The $\mathrm{CAB}$ and $\mathrm{COB}$ thicknesses increased from section 1 to section 5 gradually. In males, the CAB and COB thickness was greater than those in females significantly. SAC ranged from $10.9 \pm 8.8 \mathrm{~mm}$ to $17.4 \pm 2.7 \mathrm{~mm}$ in males and in females, it ranged from $6.0 \pm 8.0 \mathrm{~mm}$ to $16.7 \pm 3.2 \mathrm{~mm}$, DOC ranged from $1.8 \pm 1.5 \mathrm{~mm}$ to $2.9 \pm 0.9 \mathrm{~mm}$ for males, it ranged from $0.8 \pm 1.6 \mathrm{~mm}$ to $3.3 \pm 0.6$ $\mathrm{mm}$ in females, IBM ranged from $7.5 \pm 6.3 \mathrm{~mm}$ to $15.6 \pm 1.8 \mathrm{~mm}$ in male patients, it ranged from $4.1 \pm 6.6 \mathrm{~mm}$ to $14.6 \pm 1.6 \mathrm{~mm}$ in female patients.

Conclusion: Complete evaluation and knowledge of the thicknesses of cancellous and cortical bone, as well as the shape of a mandible, are important for implant installation, thus providing anatomic guidelines to clinicians, which will be helpful for implant surgery.

Keywords: Cancellous Bone, Cortical Bone, Mandible, Alveolar Crest

\section{INTRODUCTION}

For planning the implant placement in the mandible preoperatively, it is essential to determine the morphology and quantity of bone. ${ }^{1}$ For achieving stability of implant, the thickness of the cortical bone is important. Stability of implant is necessary for osseointegration and to achieve the predictable clinical outcome. ${ }^{2}$ The cortical bone thickness has a larger influence on the initial stabilisation than the implant fixture length. It was reported in earlier studies that the cancellous and cortical bone thickness is the key to successful implantation. Cancellous bone $(\mathrm{CAB})$ and cortical bone (COB) thickness affects the implant success. ${ }^{3,4}$ Quantity of bone settles on insertion angle of implant. Advances have been made in grafting of bones for sinus lift and flapless implant surgery. ${ }^{5,6}$ Precise and accurate information about bone size and morphology is required for successful implant surgeries. Cortical bone implants require removal of torque and remain constant over time. The removal torque is increased for implants in cancellous bone over time. Cortical engagement is adequately necessary for the placement of dental implants. The mandible bones were measured precisely and accurately on radiographs in many studies. For pre-operative diagnosis, panoramic radiography is frequently used, but this exhibits image distortion and magnification and it further provides wrong information. Measurement of $\mathrm{CAB}$ and $\mathrm{COB}$ thickness by panoramic radiography is impossible, however $\mathrm{CAB}$ and $\mathrm{COB}$ thickness knowledge is essential for implant placement successfully. Tomography is conventionally more accurate which measures bone size but there is a difficulty in adjusting the tomographic objective planes which may give inaccurate measured values. CT can measure the bone size precisely and shape of bone with a multi-thin voluntary sectional image. In this study, the $\mathrm{CAB}$ and $\mathrm{COB}$ thickness in the mandible was precisely and accurately in five sections from $6 \mathrm{~mm}$ anteriorly to $18 \mathrm{~mm}$ posteriorly to the mental foramen.

\section{MATERIAL AND METHODS}

This study included 90 patients out of which 50 were males and 40 were females, who had a age range of 20-80 years, mean age of 50 years were selected in S.Nijalingappa Medical College Bagalkot. They underwent computed tomography between July 2017 to January 2019. 
The side of mandibles containing tumours or cysts were excluded from the study. Total of 140 sides of mandibles were examined.

The computed tomography was performed by using Siemens SOMATOM Emotion 16, in which operations were done at $120 \mathrm{kV}, 86-110 \mathrm{~mA}$ with a thickness of $1 \mathrm{~mm}$ and speed of $2 \mathrm{~mm} / \mathrm{sec}$. $1 \mathrm{~mm}$ thick axial computed tomography images parallel to the inferior border of the mandibles were reconstructed after examination. The images were obtained from dental CT reformatting imaging software. These images were printed on film with a Fuji dry imager. The measurement of $\mathrm{CAB}$ and $\mathrm{COB}$ thicknesses of the mandibles were done at five sections namely Section 2: cross-sectional image which recognised mental foramen, the image which was $6 \mathrm{~mm}$ anterior to section 2 which was called section 1. Measurement was done from the distances between the inner and outer borders of the buccal and lingual sides for the cortical bone and from the inner border of the buccal side to inner border of the lingual side for cancellous bone.

\begin{tabular}{|l|c|c|c|}
\hline Age & \multicolumn{3}{|c|}{ Patients } \\
\hline Years & Total & Males & Females \\
\hline $18-20$ & 2 & 0 & 2 \\
\hline $21-30$ & 10 & 8 & 2 \\
\hline $31-40$ & 15 & 11 & 4 \\
\hline $41-50$ & 15 & 8 & 7 \\
\hline $51-60$ & 19 & 16 & 3 \\
\hline $61-70$ & 22 & 12 & 10 \\
\hline $71-80$ & 7 & 7 & 0 \\
\hline Total & 90 & 62 & 28 \\
\hline \multicolumn{4}{|c|}{ Table-1: Patients characteristics. } \\
\hline
\end{tabular}

\begin{tabular}{|l|c|c|c|c|}
\hline Patients & Number & \multicolumn{3}{|c|}{ Measurement Scales } \\
\hline Total & Sides & Heights & Cancellous & Cortical \\
\hline 2 & 2 & 6 & 22 & 22 \\
\hline 10 & 14 & 66 & 261 & 261 \\
\hline 15 & 22 & 106 & 421 & 421 \\
\hline 15 & 22 & 106 & 421 & 421 \\
\hline 19 & 34 & 172 & 682 & 682 \\
\hline 22 & 37 & 186 & 742 & 742 \\
\hline 7 & 9 & 46 & 182 & 182 \\
\hline 90 & 140 & 688 & 2731 & 2731 \\
\hline
\end{tabular}

Table-2: Shows that 140 sides in total of mandibles, 688 heights, 2731 cancellous and 2731 cortical thicknesses were measured
From the alveolar crest, the measurement of the cancellous bone and cortical bone thicknesses was avoided as atrophic changes occurred due to periodontal disease or tooth extraction and this exclusion increased the reproducibility of results. The measurement of $\mathrm{CAB}$ and $\mathrm{COB}$ thicknesses were done at 5, 10, 15, $20 \mathrm{~mm}$ respectively above the inferior border of the mandible toward the alveolar crest. There were three types of the mandibles namely Type A: lingual concavity, Type B: Buccal concavity, Type C: Round shape. The distance from the superior border of the canal to the alveolar crest (SAC) and the distance from the inferior border of the canal to the bottom of the mandible (IBM) and the diameter of the canal (DOC) were measured at 5 sections to identify the location of the mandible canal. The data was presented as means and standard deviations(SD). The statistical differences were tested using student's t-test and chi-square test. $P$ value less than 0.05 was considered as significant.

\section{RESULTS}

Table 1 shows that the least number of patients were present in the age group range of 18-20 years with a total of 2 out of which 2 were females and the most number of patients were patients were in the age group of $61-70$ years with a total of 22 out of which 12 were males and 10 were females.

Table 3 shows that the means and SD of the CAB and COB in male patients ranged from $5.48 \pm 1.20 \mathrm{~mm}$ to $11.47 \pm 2.74$ $\mathrm{mm}$ and $4.28 \pm 1.08 \mathrm{~mm}$ to $6.02 \pm 1.44$ in male patients respectively.

Table 4 shows that the means and SD of the CAB and COB in female patients ranged from $4.82 \pm 1.28 \mathrm{~mm}$ to $10.27 \pm 1.49$ $\mathrm{mm}$ and $3.86 \pm 1.02 \mathrm{~mm}$ to $5.31 \pm 0.93 \mathrm{~mm}$ in female patients respectively. In both genders, the $\mathrm{CAB}$ thickness was the greatest in sections 2 and 5 and the $\mathrm{COB}$ thickness was greatest in sections 1 and 5. The $\mathrm{CAB}$ and $\mathrm{COB}$ thicknesses increased from section 1 to section 5 gradually. In males, the $\mathrm{CAB}$ and $\mathrm{COB}$ thickness was greater than those in females significantly.

Table 5 shows that SAC ranged from $10.9 \pm 8.8 \mathrm{~mm}$ to $17.4 \pm 2.7 \mathrm{~mm}$ in males and in females, it ranged from $6.0 \pm 8.0$ $\mathrm{mm}$ to $16.7 \pm 3.2 \mathrm{~mm}$, DOC ranged from $1.8 \pm 1.5 \mathrm{~mm}$ to $2.9 \pm 0.9 \mathrm{~mm}$ for males, it ranged from $0.8 \pm 1.6 \mathrm{~mm}$ to $3.3 \pm 0.6$ $\mathrm{mm}$ in females, IBM ranged from $7.5 \pm 6.3 \mathrm{~mm}$ to $15.6 \pm 1.8$ $\mathrm{mm}$ in male patients, it ranged from $4.1 \pm 6.6 \mathrm{~mm}$ to $14.6 \pm 1.6$ $\mathrm{mm}$ in female patients.

\begin{tabular}{|c|c|c|c|c|c|c|}
\hline \multirow[b]{2}{*}{ Total } & \multirow[b]{2}{*}{ Type } & \multicolumn{5}{|c|}{ Section } \\
\hline & & 1 & 2 & 3 & 4 & 5 \\
\hline \multirow[t]{4}{*}{ Male patients Cancellous Width (mm) } & A & $5.85 \pm 1.55$ & $5.52 \pm 1.35$ & $5.48 \pm 1.20$ & $5.69 \pm 1.32$ & $6.02 \pm 1.54$ \\
\hline & B & $7.80 \pm 1.63$ & $7.76 \pm 1.52$ & $8.22 \pm 1.63$ & $8.57 \pm 1.84$ & $9.30 \pm 1.85$ \\
\hline & C & $7.44 \pm 1.48$ & $7.85 \pm 1.49$ & $9.33 \pm 2.00$ & $11.07 \pm 2.23$ & $11.11 \pm 2.36$ \\
\hline & D & $7.25 \pm 1.78$ & $7.66 \pm 2.09$ & $8.94 \pm 2.41$ & $11.47 \pm 2.74$ & $11.10 \pm 2.57$ \\
\hline \multirow{4}{*}{$\begin{array}{l}\text { Male patients } \\
\text { Cortical width }(\mathrm{mm})\end{array}$} & A & $6.02 \pm 1.44$ & $5.78 \pm 1.10$ & $5.48 \pm 0.99$ & $5.24 \pm 1.09$ & $5.36 \pm 0.98$ \\
\hline & $\mathrm{B}$ & $4.65 \pm 0.95$ & $4.71 \pm 0.84$ & $4.75 \pm 0.96$ & $4.50 \pm 1.24$ & $4.30 \pm 0.96$ \\
\hline & $\mathrm{C}$ & $4.50 \pm 0.88$ & $4.77 \pm 0.97$ & $4.71 \pm 1.08$ & $5.15 \pm 1.10$ & $5.02 \pm 1.23$ \\
\hline & $\mathrm{D}$ & $4.49 \pm 0.96$ & $4.49 \pm 0.92$ & $4.48 \pm 1.24$ & $4.28 \pm 1.08$ & $4.54 \pm 1.31$ \\
\hline
\end{tabular}




\begin{tabular}{|c|c|c|c|c|c|c|}
\hline \multirow[b]{2}{*}{ Total } & \multirow[b]{2}{*}{ Type } & \multicolumn{5}{|c|}{ Section } \\
\hline & & 1 & 2 & 3 & 4 & 5 \\
\hline \multirow[t]{4}{*}{ Female patients Cancellous Width (mm) } & $A$ & $5.02 \pm 1.41$ & $4.82 \pm 1.28$ & $4.92 \pm 1.48$ & $5.21 \pm 1.55$ & $5.42 \pm 1.63$ \\
\hline & $\mathrm{B}$ & $6.56 \pm 1.57$ & $6.70 \pm 1.20$ & $7.11 \pm 1.38$ & $7.75 \pm 1.38$ & $8.35 \pm 1.48$ \\
\hline & C & $6.82 \pm 1.28$ & $7.18 \pm 1.48$ & $8.25 \pm 1.66$ & $9.34 \pm 1.67$ & $10.27 \pm 1.49$ \\
\hline & $\mathrm{D}$ & $6.33 \pm 1.28$ & $7.00 \pm 1.71$ & $7.87 \pm 2.34$ & $8.86 \pm 2.88$ & $10.22 \pm 2.74$ \\
\hline \multirow{4}{*}{$\begin{array}{l}\text { Female patients } \\
\text { Cortical width }(\mathrm{mm})\end{array}$} & A & $5.26 \pm 1.25$ & $5.16 \pm 1.29$ & $4.87 \pm 0.95$ & $4.77 \pm 0.97$ & $5.31 \pm 0.93$ \\
\hline & $B$ & $3.86 \pm 1.02$ & $3.94 \pm 0.85$ & $4.04 \pm 0.89$ & $3.97 \pm 0.79$ & $4.00 \pm 0.88$ \\
\hline & $\mathrm{C}$ & $4.05 \pm 0.62$ & $4.28 \pm 1.09$ & $4.65 \pm 1.04$ & $4.89 \pm 1.15$ & $4.90 \pm 1.28$ \\
\hline & $\mathrm{D}$ & $4.19 \pm 0.74$ & $4.15 \pm 1.00$ & $3.90 \pm 0.96$ & $4.11 \pm 1.11$ & $4.59 \pm 1.15$ \\
\hline
\end{tabular}

\begin{tabular}{|c|c|c|c|c|c|c|}
\hline \multirow[b]{2}{*}{ Total } & \multirow[b]{2}{*}{ Type } & \multicolumn{5}{|c|}{ Section } \\
\hline & & 1 & 2 & 3 & 4 & 5 \\
\hline \multirow[t]{3}{*}{ Male patients Distance (mm) } & SAC & $10.9 \pm 8.8$ & $13.4 \pm 3.5$ & $17.4 \pm 2.7$ & $16.8 \pm 3.6$ & $15.9 \pm 3.8$ \\
\hline & DOC & $1.8 \pm 1.5$ & $2.5 \pm 0.7$ & $2.8 \pm 0.8$ & $2.9 \pm 0.6$ & $2.9 \pm 0.9$ \\
\hline & IBM & $7.5 \pm 6.3$ & $15.6 \pm 1.8$ & $10.6 \pm 1.8$ & $9.7 \pm 1.5$ & $9.2 \pm 1.4$ \\
\hline \multirow[t]{3}{*}{ Female patients Distance $(\mathrm{mm})$} & SAC & $6.0 \pm 8.0$ & $12.2 \pm 3.9$ & $16.7 \pm 3.2$ & $15.5 \pm 2.1$ & $13.8 \pm 3.8$ \\
\hline & DOC & $0.8 \pm 1.6$ & $2.5 \pm 0.8$ & $2.7 \pm 0.4$ & $2.2 \pm 0.4$ & $3.3 \pm 0.6$ \\
\hline & IBM & $4.1 \pm 6.6$ & $14.6 \pm 1.6$ & $10.9 \pm 1.1$ & $9.8 \pm 2.7$ & $9.0 \pm 1.6$ \\
\hline
\end{tabular}

\section{DISCUSSION}

In the present study, the means and $\mathrm{SD}$ of the $\mathrm{CAB}$ and $\mathrm{COB}$ in female patients ranged from $4.82 \pm 1.28 \mathrm{~mm}$ to $10.27 \pm 1.49$ $\mathrm{mm}$ and $3.86 \pm 1.02 \mathrm{~mm}$ to $5.31 \pm 0.93 \mathrm{~mm}$ in female patients respectively. In both genders, the $\mathrm{CAB}$ thickness was the greatest in sections 2 and 5 and the $\mathrm{COB}$ thickness was greatest in sections 1 and 5. The $\mathrm{CAB}$ and $\mathrm{COB}$ thicknesses increased from section 1 to section 5 gradually. In males, the $\mathrm{CAB}$ and $\mathrm{COB}$ thickness was greater than those in females significantly. SAC ranged from $10.9 \pm 8.8 \mathrm{~mm}$ to $17.4 \pm 2.7$ $\mathrm{mm}$ in males and in females, it ranged from $6.0 \pm 8.0 \mathrm{~mm}$ to $16.7 \pm 3.2 \mathrm{~mm}$, DOC ranged from $1.8 \pm 1.5 \mathrm{~mm}$ to $2.9 \pm 0.9$ $\mathrm{mm}$ for males, it ranged from $0.8 \pm 1.6 \mathrm{~mm}$ to $3.3 \pm 0.6 \mathrm{~mm}$ in females, IBM ranged from $7.5 \pm 6.3 \mathrm{~mm}$ to $15.6 \pm 1.8 \mathrm{~mm}$ in male patients, it ranged from $4.1 \pm 6.6 \mathrm{~mm}$ to $14.6 \pm 1.6$ $\mathrm{mm}$ in female patients. In a study done by Mohammad A Momin et al; ${ }^{7}$ the $\mathrm{CAB}$ and $\mathrm{COB}$ thicknesses were evaluated in five sections from $6 \mathrm{~mm}$ anterior to $18 \mathrm{~mm}$ posterior to the mental foramen. It was determined in their study that for providing anatomic guidelines to clinicians, careful evaluation and full knowledge of the thicknesses of $\mathrm{CAB}$ and $\mathrm{COB}$ thickness, as well as the shape of a mandible, are necessary for implant surgery. Zhao $\mathrm{H}$ et al; ${ }^{8}$ conducted a study in which to analyze the differences in cortical bone thickness, one-way analysis of variance (ANOVA) was used. Buccal cortical bone in the mandible was thicker than that in the maxilla. In the maxilla, cortical bone thickness was thicker in the buccal side than in the palatal side. Buccal cortical bone thickness in the mandible was thickest at the site distal to the first molar, and in the maxilla it was thickest at the site mesial to the first molar, while in the palatal side of maxilla it was thickest at the site mesial to the second premolar. The changing pattern of cortical bone thickness varies at different sites. In the buccal side of maxilla, the thinnest cortical bone thickness was found to be at $4 \mathrm{~mm}$ level from the alveolar crest, while the thickest was at $10 \mathrm{~mm}$ level (except for the site mesial to the first premolar). The buccal cortical bone thickness at the sites mesial or distal to the first molar in the mandible and palatal cortical bone thickness of maxilla tended to increase with increasing distance from the alveolar bone. Watanabe $\mathrm{H}$ et al; ${ }^{9}$ observed that the means of the height and width ranged from 27.6 to $31.0 \mathrm{~mm}$ and from 10.5 to $15.8 \mathrm{~mm}$, respectively. The height in male subjects was significantly greater than that in female subjects, and the width in male subjects was slightly but not significantly greater than that in female subjects. The morphology of the mandible was classified into three types. Type $\mathrm{C}$ (round) (59$61 \%$ ) was the most common in the posterior region, followed by type A (lingual concavity) (36-39\%), whereas type B (buccal concavity) (58-74\%) and type C (17-36\%) were the most common types in the anterior region. The distance from the mandibular canal to the alveolar crest, ranged from 15.3 to $17.4 \mathrm{~mm}$. The anterior loop, was observed on 55\% of all sides. Kim H J et al; ${ }^{10}$ observed that the cortical bone thickness according to measurement levels in both the labial and lingual sides increased from L1 to L5, and the lingual side below L3 was significantly thicker than the labial side on the maxilla and mandible. In particular, the labial cortical bone thickness in the maxilla was the thinnest compared to the other regions. The cancellous bone thickness according to measurement levels increased from L1 to L5 on the maxilla, and on the mandible it was the thinnest at the middle level of the root. Apostolakis $\mathrm{D}$ et al; ${ }^{11}$ observed that an anterior loop could be identified in $48 \%$ of the cases with a mean length (range) of $0.89 \mathrm{~mm}(0-5.7)$. In almost half of the surveyed cases an anterior loop was present. Even though in $95 \%$ of the study cases the loop was $<3 \mathrm{~mm}$, a $100 \%$ safety margin in the placement of anterior mandibular implants, in the absence of a CBCT scan, would only be achieved with a distance of $6 \mathrm{~mm}$ between the anterior border of the 
mental foramen and the most distal interforaminal implant fixture.

\section{CONCLUSION}

Complete evaluation and knowledge of the thicknesses of cancellous and cortical bone, as well as the shape of a mandible, are important for implant installation, thus providing anatomic guidelines to clinicians, which will be helpful for implant surgery.

\section{REFERENCES}

1. Cavalcanti MG, Yang J, Ruprecht A, Vannier MW. Validation of spiral computed tomography for dental implants. Dentomaxillofac Radiol 1998;27(1): 329-333.

2. Katranji A, Misch K, Wang HL. Cortical bone thickness in dentate and edentulous human cadavers. J Periodontol 2007;78(5): 874-878.

3. Miyamoto I, Tsuboi Y, Wada E, Suwa H, Iizuka T. Influence of cortical bone thickness and implant length on implant stability at the time of surgery-clinical, prospective, biomechanical, and imaging study. Bone 2005;37(2): 776-780.

4. Albrektsson T, Brånemark PI, Hansson HA, Lindström J. Osseointegrated titanium implants. Requirements for ensuring a long-lasting, direct bone-to- implant anchorage in man. Acta Orthop Scand 1981;52(6): 155-170.

5. Roberts WE, Smith RK, Zilberman Y, Mozsary PG, Smith RS. Osseous adaptation to continuous loading of rigid endosseous implants. Am J Orthod 1984;86(3): 95-111.

6. Deguchi T, Nasu M, Murakami K, Yabuuchi T, Kamioka H, et al. Quantitative evaluation of cortical bone thickness with computed tomographic scanning for orthodontic implants. Am J Orthod Dentofacial Orthop 2006;129(4): 721-8.

7. Mohammad A Momin, Tohru Kurabayashi, Takashi Yosue; Quantitative and Morphological Evaluation of Cancellous and Cortical Bone of the Mandible by CT; OMICS Journal of Radiology; Volume 3; Issue 1;2013,3(1):23-29.

8. Zhao $\mathrm{H}, \mathrm{Gu} \mathrm{XM}$, Liu HC, Wang ZW, Xun CL. Measurement of cortical bone thickness in adults by cone-beam computerized tomography for orthodontic miniscrews placement. J Huazhong Univ Sci Technolog Med Sci 2013;33(1): 303-308.

9. Watanabe H, Mohammad Abdul M, Kurabayashi T, Aoki H. Mandible size and morphology determined with CT on a premise of dental implant operation. Surg Radiol Anat 2010;32(3): 343-349.

10. Kim HJ, Yu SK, Lee MH, Lee HJ, Kim HJ, et al. Cortical and cancellous bone thickness on the anterior region of alveolar bone in Korean: a study of dentate human cadavers. J Adv Prosthodont 2012;4(6): 146152.

11. Apostolakis D, Brown JE. The anterior loop of the inferior alveolar nerve: prevalence, measurement of its length and a recommendation for interforaminal implant installation based on cone beam CT imaging. Clin Oral Implants Res 2012;23(5): 1022-1030.
Submitted: 21-11-2019; Accepted: 18-12-2019; Published online: 23-12-2019 